\title{
Oficina de jogos pedagógicos de ensino de ecologia e educação ambiental como estratégia de ensino na formação de professores
}

\section{Pedagogical games workshop of ecology teaching and environmental education as a strategy for the formation of teachers}

\author{
Antonio Fernandes Nascimento Junior ${ }^{1}$ | toni_nascimento@yahoo.com.br \\ Laise Vieira Gonçalves ${ }^{1}$
}

\section{RESUMO}

Este trabalho apresenta uma oficina pedagógica de educação ambiental organizada pelos bolsistas do Programa Institucional de Iniciação à Docência (PIBID) de biologia da Universidade Federal de Lavras, MG. A oficina foi dividida em três momentos. No primeiro, foi feito uma apresentação de slides sobre a importância da utilização de jogos pedagógicos no ensino da educação ambiental. No segundo, os jogos foram expostos e, por fim, foi escolhido o jogo de sequencia etológica para ser jogado pelos participantes. Ao final pode-se perceber que esta prática contribuiu para disseminação de conceitos ecológicos da educação ambiental, sendo uma estratégia interessante para a formação de professores. (FAPEMIG e CAPES/PIBID).

Palavras-chave: Educação Ambiental; oficina de jogos; formação de professores.

\section{ABSTRACT}

This paper presents a pedagogical workshop of environmental education organized by students of the Program Institutional Initiation to Teaching of biology of the University of Lavras, MG. The workshop was divided into three stages. In the first, was made a slideshow about the importance of the use of educational games in teaching of the environmental education. In the second, the games have been exposed and was chosen the ethological sequence game to be played by participants. At the end can be see that this practice contributed to the spread of ecological concepts and of environmental education, being an interesting strategy for the training of teachers.

Keywords: Environmental education; games workshop; training teachers.

1 UFLA - Universidade Federal de Lavras, Lavras, MG. 


\section{INTRODUÇÃO}

Nas últimas décadas os professores têm convivido com o discurso constante da necessidade de atualização permanente (SOUZA e GOUVÊA, 2006). Assim, ao ensinar biologia, o professor deve priorizar o desenvolvimento de atitudes e valores, que são essenciais no aprendizado, utilizando metodologias que promovam o questionamento, o debate, e a investigação superando, desta maneira as limitações de um ensino passivo ainda presente no contexto escolar (KLEIN et al., 2005).

Segundo Castoldi e Polinarski (2009), grande parte dos professores tendem a adotar métodos mais tradicionais de ensino pelo receio do novo ou também por estarem há muito acostumados com o velho sistema educacional, que não favorece a motivação do educando. Sendo esta, fundamental no processo de ensino-aprendizagem.

A busca por ferramentas de ensino que possam deixar o processo de ensino-aprendizagem mais motivador tem sido uma das grandes dificuldades encontradas por parte dos professores de nível fundamental e médio (SOUZA e NASCIMENTO JUNIOR, 2005). Estes autores defendem que os jogos pedagógicos proporcionam atividades educacionais mais criativas e motivadoras por terem caráter lúdico. Eles podem ser utilizados para revisão de conteúdos em sala de aula ou utilizados em oficinas pedagógicas onde os participantes os jogam, sendo uma ferramenta potencializadora para a educação ambiental (SOUZA e NASCIMENTO JUNIOR, 2005).

Ainda de acordo com Klein et al. (2005) as oficinas pedagógicas podem atuar como um meio na formação continuada do profissional da área de educação, como um prolongamento de sua formação inicial, visando o aperfeiçoamento, tanto teórico como prático no contexto de trabalho, para além do exercício profissional em ações voltadas tanto a formação dentro da jornada de trabalho como fora desta.

Ao enfocar a temática ambiental, trabalhando conjuntamente com as oficinas pedagógicas, busca-se sensibilizar o olhar, tanto do educando, como do educador, contextualizando e aproximando do cotidiano, envolvendo o educando, que participa, age e transforma, promovendo trocas coletivas, a integração e inserção das diferentes leituras de mundo, de questões urgentes e essenciais, para nossa constituição como ser humano no presente (VEGA e SCHIRMER, 2008).

\section{OBJETIVOS}

Este trabalho busca relatar uma experiência pedagógica organizada pelos alunos do Programa Institucional de Bolsa de Iniciação à Docência (PIBID) de biologia da Universidade Federal de Lavras, MG (UFLA) a qual consistiu na elaboração e execução de uma oficina pedagógica referente à utilização de jogos didáticos no ensino de ecologia e educação ambiental, sendo esta uma estratégia pedagógica na formação inicial e continuada de professores.

\section{METODOLOGIA}

A oficina foi desenvolvida no espaço livre do Museu de História Natural da Universidade Federal de Lavras (UFLA) e foi dividida em dois momentos, os quais foram filmados e, posteriormente, analisados. O público alvo da oficina eram os licenciandos do curso Ciências Biológicas e professores de ciências e biologia da cidade de Lavras, MG. No primeiro momento, o trabalho se concentrou no planejamento e elaboração de uma oficina pedagógica sobre a utilização de jogos didáticos de ecologia e educação ambiental no ensino de ciências e biologia. Estes jogos fazem parte do acervo do Laboratório de Educação Científica e Ambiental (LECA) do Departamento de Biologia da UFLA.

No segundo momento a oficina foi desenvolvida, sendo esta dividida em três partes. A primeira se concentrou em uma apresentação de slides dividida em dois momentos. O primeiro referente à utilização de espaços não formais no processo educativo e, o segundo, sobre a importância da utilização dos jogos didáticos no ensino, 
por meio de justificativas teóricas. A segunda parte da oficina consistiu de uma exposição de jogos didáticos relacionados à ecologia e à educação ambiental, sendo estes: jogos de montar ecológicos, trilha ecológica, sequência etológica, dominó ecológico e bingão da bicharada. Estes jogos estão ilustrados abaixo.

\section{Jogos expostos na oficina pedagógica}

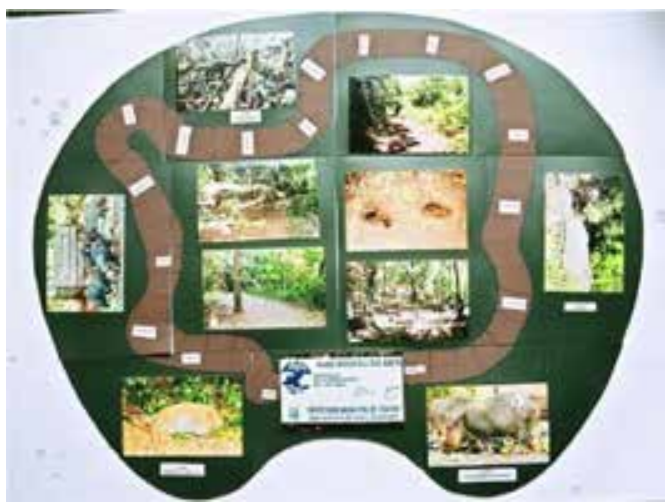

Trilha ecológica

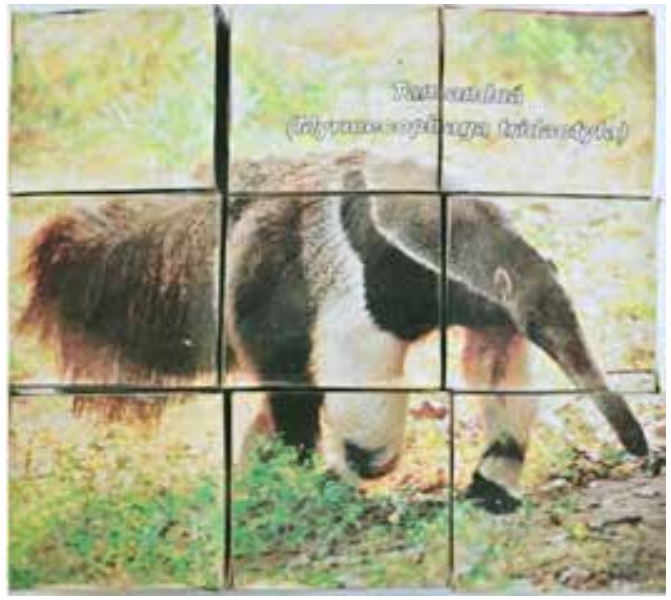

Jogo de montar - Tamanduá-bandeira

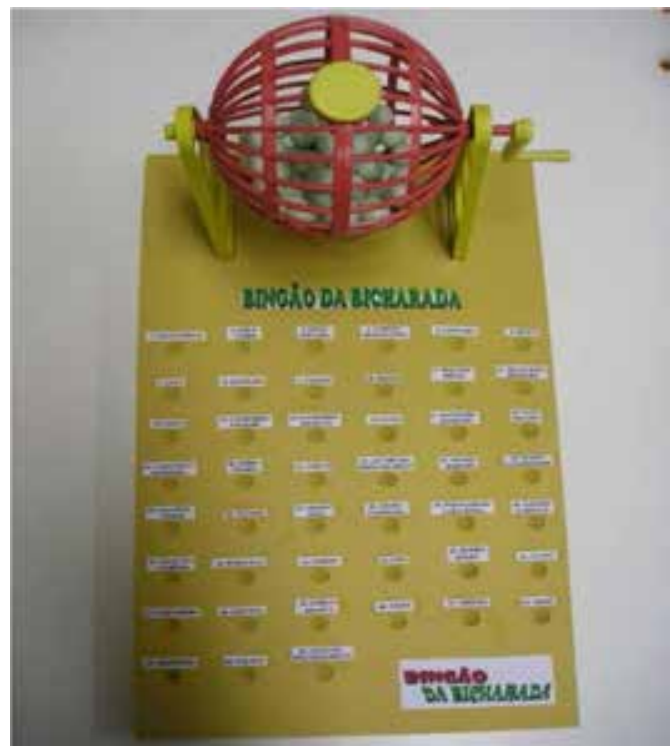

Bingão da Bicharada - Tabuleiro

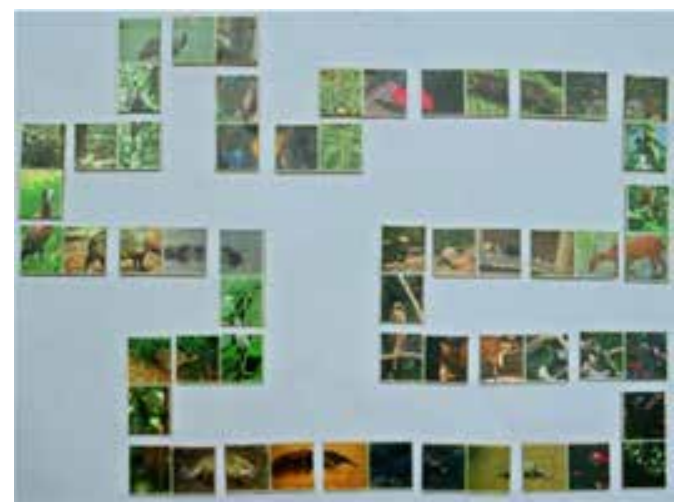

Dominó ecológico

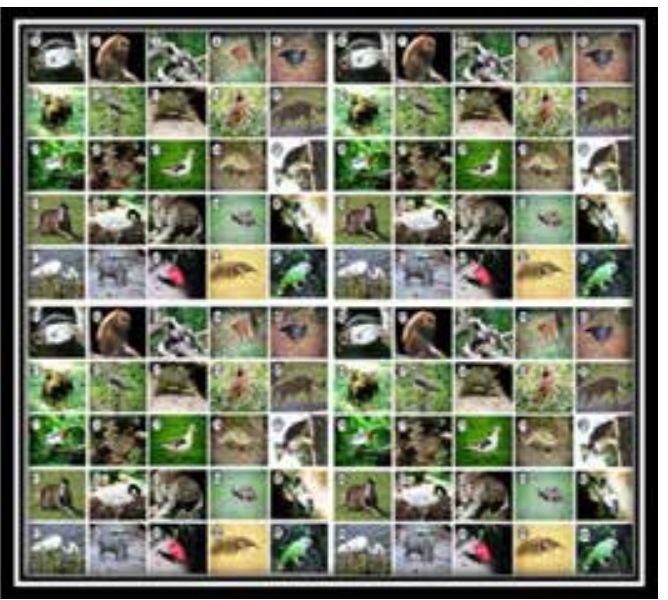

Sequencia Etológica

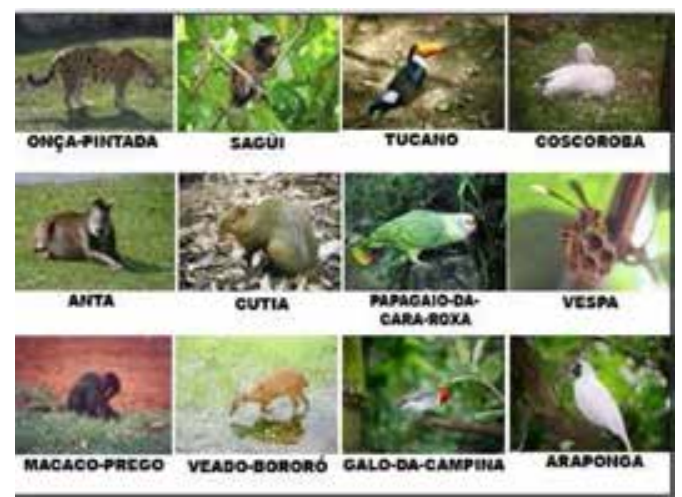

Bingão da Bicharada - Cartelas 
Na terceira parte, os participantes foram divididos em 2 grupos de 5 membros. Neste momento, os mesmos foram convidados a jogar um dos jogos presentes na exposição. O jogo escolhido foi o de "Sequência Etológica” confeccionado pelos integrantes do Laboratório de Educação Científica e Ambiental do Departamento de Biologia da UFLA.

Por fim, foi feita uma avaliação da prática com os participantes a fim de compreender se esta havia sido eficaz. Toda a atividade foi filmada e, posteriormente, analisada.

\section{RESULTADOS E DISCUSSÃO TEÓRICA}

\section{A apresentação dos slides}

Primeiramente foi feita uma breve apresentação sobre os espaços formal, informal, não formal e seus respectivos ambientes de aprendizagem. A segunda parte foi referente à utilização de jogos no ensino e as teorias pedagógicas que orientam sua prática, bem como a sua utilização na formação de conceitos e na formação de professores. Neste momento, também foi abordado a importância de um planejamento adequado para que a atividade lúdica não seja ineficiente como processo pedagógico e a importância da atuação do professor como mediador nesse instrumento pedagógico. O professor deve atuar estimulado e auxiliando o aluno a formular e reformular os conceitos, buscando seus conhecimentos prévios e articulando esses conhecimentos a uma nova informação que está sendo apresentada.

\section{A exposição dos jogos}

A segunda parte da atividade consistiu na exposição dos jogos didáticos de biologia, sendo estes: jogos de montar, trilha ecológica, sequência etológica, dominó ecológico e bingão da bicharada.

Os jogos de montar assim como os dominós e o jogo do bingo são utilizados como tema-gerador de questões conceituais da biologia e para educação ambiental, ao mesmo tempo, facilitadores da familiarização com os animais regionais fortalecendo a ideia de contextualização. O jogo de sequência e trilha, além da familiarização buscam facilitar também a apreensão de conceitos etológicos e evolutivos associados aos animais pertencentes á estes jogos.

Assim, todos estes jogos são ferramentas didáticas importantes na educação ambiental, já que são compostos por animais regionais que possibilitam uma contextualização dos participantes com o local de origem dos mesmos.

\section{A aplicação do jogo}

Na terceira parte da atividade os participantes da oficina foram divididos em dois grupos, onde foi proposto que os mesmos escolhessem um dos jogos para que pudesse ilustrar a prática. O jogo escolhido foi o de "Sequência Etológica”, o qual se prestou como um exemplo de aplicação desta atividade didática na sala de aula. O jogo escolhido é uma adaptação do jogo convencional Sequência. Os participantes apresentaram bastante interesse com situações de grande interação e entusiasmo, o que expressa um momento de motivação.

Ao final da atividade os depoimentos foram favoráveis à aplicabilidade desta prática na sala de aula. A maioria dos participantes identificou a atividade como diferenciada e motivadora, levando-os ao aprendizado de conceitos ecológicos sobre os animais da região e suas características, além de proporcionar uma aproximação dos participantes com os animais presentes nos jogos. 


\section{Um pouco de Discussão}

Os materiais didáticos são ferramentas fundamentais para os processos de ensino e aprendizagem, e o jogo didático caracteriza-se como uma importante e viável alternativa para auxiliar em tais processos por favorecer a construção do conhecimento ao aluno (CAMPOS et al., 2003)

Segundo Souza e Nascimento Junior (2005), os jogos didáticos e pedagógicos têm sido considerados subsídios durante o processo de ensino-aprendizagem e, por terem caráter lúdico, proporcionam atividades educacionais mais criativas e motivadoras, além de subsidiar o processo de ensino-aprendizagem devido a seu caráter lúdico que proporciona atividades educacionais mais criativas e motivadoras. Motivação esta que pode ser percebida durante a aplicação do jogo Sequência Etológica.

Percebe-se que através destas atividades educativas, como jogos e oficinas pedagógicas, pode-se aproximar o aluno do conhecimento, pois, de acordo com Souza e Nascimento Junior (2005), estas atividades envolvem o acadêmico em um processo de formação onde existe o confronto direto com situações educativas.

Além disso, de acordo com Moraes e Rezende (2009), a introdução de jogos e atividades lúdicas no cotidiano escolar é importante porque se torna mais fácil e dinâmico o processo de ensino e aprendizagem, já que os alunos estão envolvidos emocionalmente na ação.

Para Vega e Schirmer (2008), ao mesclar nas práticas diárias de sala de aula a Educação Ambiental e as atividades lúdicas das oficinas pedagógicas, construí-se ações de questionamentos sobre o tema abordado, configurando as diversas relações entre educação/ indivíduo/coletivo/ transformação.

A experiência relatada neste trabalho, encontra respaldo nas ideias de Klein et al. (2005) as quais afirmam que as oficinas pedagógicas que abordam temas contemporâneos da sociedade, dentre estes a educação ambiental, podem atuar como um meio na formação inicial e continuada de professores de ciências e biologia propiciando a reflexão sobre a ação do profissional ao trabalhar tais temas em sala de aula.

\section{CONCLUSÕES}

Os participantes da oficina tiveram a oportunidade de ter contato com um tipo de estratégia pedagógica diferenciada para a aquisição de conceitos ecológicos e de educação ambiental, de maneira a favorecer a motivação e as interações sociais entre os participantes. Assim, pode-se perceber que esta prática contribuiu para disseminação destes conceitos, sendo uma estratégia interessante para a formação de professores de ciências e biologia.

\section{REFERÊNCIAS BIBLIOGRÁFICAS}

CAMPOS, L. M. L.; BORTOLOTO, T. M.; FELICIO, A. K. C. A produção de jogos didáticos para o ensino de Ciências e Biologia: uma proposta para favorecer a aprendizagem. Caderno dos Núcleos de Ensino, p. 35-48, 2003.

CASTOLDI, R.; POLINARSKI, C. A. A Utilização de Recursos Didático-Pedagógicos na Motivação da Aprendizagem. In: Anais do SINECT - I Simpósio Nacional de Ensino de Ciência e Tecnologia. Ponta Grossa - PR, 2009. ISBN: 978-85-7014-048-7684.

KLEIN, T. A. da S.; OLIVEIRA, V. L. B. de; PEGORARO O. M. E.; CUPELLI, R. L. Oficinas pedagógicas: uma proposta para a formação continuada de professores de biologia. In: Anais do V Encontro Nacional de Pesquisa em Educação em Ciências, n5, 2005, p. 1-7. 
MORAES, E.; REZENDE, D. Atividades lúdicas como elementos mediadores da aprendizagem no ensino de ciências da natureza. Enseñanza de las Ciencias, Número Extra VIII Congreso Internacional sobre Investigación en Didáctica de las Ciencias, Barcelona, pp. 1008-1012, 2009.

SOUZA, D. C.; NASCIMENTO JUNIOR, A. F. Jogos didático-pedagógicos ecológicos: uma proposta para o ensino de ciências, ecologia e educação ambiental. In: Anais do V Encontro Nacional de Pesquisa em Educação em Ciências, 2005, p. 1-12.

SOUZA, L. H. P. de; GOUVÊA, G. Oficinas pedagógicas de ciências: os movimentos pedagógicos predominantes na formação continuada de professores. Ciência e educação, v. 12, n. 3, p. 303-313, 2006.

VEGA, L. B. da S.; SCHIRMER; S. N. Oficinas ecopedagógicas: transformando as práticas educativas diárias nos anos iniciais. Revista Eletrônica do Mestrado em Educação Ambiental, v. 20, p. 393-408, 2008. 